\title{
PERANCANGAN DATABASE UNTUK PEMINJAMAN BARANG DI UNVERSITAS XYZ
}

\author{
Bondan Wahyu Pamekas ${ }^{1}$, Arif Budiman ${ }^{2}$, Yohanes Hans Nedy ${ }^{3}$ \\ Magister Teknik Informatika ${ }^{1}$, Magister Teknik Informatika ${ }^{2}$, Magister Teknik Informatika ${ }^{3}$ \\ Universitas Amikom Yogyakarta \\ Jl. Ring Road Utara, Condong Catur, Sleman, Yogyakarta \\ bondan.1044@students.amikom.ac.id ${ }^{1}$, arif.6122@students.amikom.ac.id², \\ yohanes.22@students.amikom.ac.id ${ }^{3}$
}

\begin{abstract}
Documentation is an important activity for documenting reserving stuffs in the University $X Y Z$. The data collection process that still use manual methods that require long, and difficult process. The process is the borrower required to bring a letter to the BAU reserving letter for borrowing, which will be registered by the BAU, after that the BAU will provide confirmation to the borrower. Not to mention in the implementation, there is the possibility of BAU officer forgot in the transaction process with the borrower.This research aims to design database at XYZ University loaning items that will be implemented this system at the BAU and can replace the existing manual methods and facilitate to recerving stuffs. The method used in the design of this database is DBLC. The final research can design a database that can be applied for reserving stuffs at XYZ University so it can be easier, faster, and structured.
\end{abstract}

Keywords: Database, Relational Data, Reserving Stuffs, DBLC.

\section{Latar Belakang Masalah}

Perkembangan teknologi informasi yang semakin pesat mendorong adanya transisi sistem lama yang bersifat manual menjadi sistem baru yang lebih terkomputerisasi. Salah satunya adalah dengan menggunakan sistem basis data untuk memlihara data yang sudah diolah sehingga dapat dengan mudah diakses kembali.[1] Universitas merupakan salah satu lembaga yang memanfaatkan teknologi informasi dalam proses peminjaman barang. [2]

Sistem yang terdapat di Universitas XYZ masih manual dan terkesan memerlukan proses yang lama. dimana pihak peminjam menyerahkan surat permohonan peminjaman, lalu mendaftarkan diri ke pihak BAU, kemudian menunggu proses persetujuan dari pihak BAU. Belum lagi permasalah dalam pelaksanaannya, peminjaman yang dilakukan secara manual dapat menimbulkan berbagai masalah antara lain efisiensi proses peminjaman dan lamanya proses pelaporan data.[3] sehingga dapat merugikan pihak peminjam dan universitas. Sehubungan dengan hal tersebut, maka dilakukan perubahan sistem yang ada pada BAU di Universitas XYZ dengan merancang database peminjaman barang untuk membantu dalam melakukan pengelolaan peminjamaan. Pada penelitian ini lebih berfokus pada perancangan model dari suatu database peminjaman barang yang dibangun menggukan konsep perancangan DBLC (Database Life Cycle)

\section{Metodologi Penelitian}

Metode perancangan ini menggunakan metode DBLC (Database Life Cycle) dengan variable penelitian adalah perancangan database peminjaman barang di Universitas XYZ. Metode DBLC menjelaskan mengenai siklus hidup dari sebuah database yang akan terus kembali ketitik awal karena database tersebut akan membutuhkan perbaikan sesuai dengan perkembangan.[4][5]. Perancangan basis data peminjaman barang dilakaukan melalui beberapa langkah-langkah yaitu : [6] 
1. Melakukan observasi, wawancara, studi pustaka, serta beberapa teknik pengumpulan data lainnya guna mendapatkan data-data yang diperlukan

2. Melakukan analisa kebutuhan data yang meliputi kebutuhan user dan aplikasinya.

3. Melakukan perancangan basis data secara Konseptual

4. Melakukan perancangan basis data secara Logikal

5. Melakukan perancangan basis data secara Fisikal

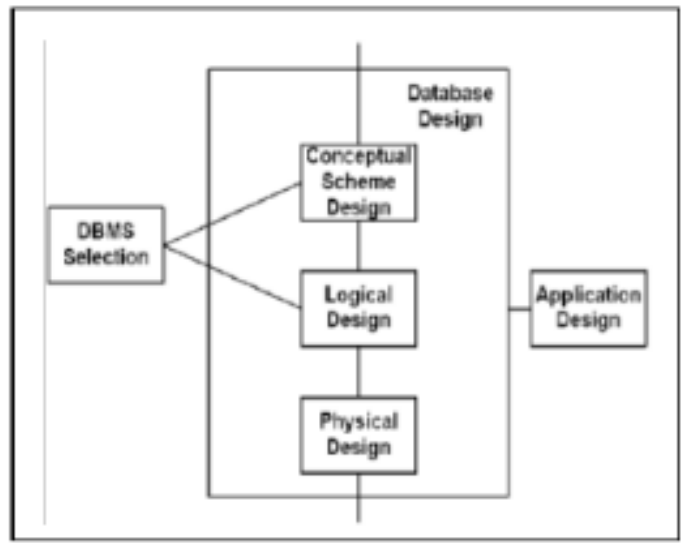

Gambar 1 Alur Perancangan Basis Data

\section{Hasil dan Pembahasan}

Perancangan merupakan suatu hal yang sangat penting dalam pembuatan database. Untuk itu diperlukan adanya perancangan basis data baik secara fisik maupun secara konseptualnya. Perancangan konseptual akan menunjukkan entity dan relasinya perlu dilakukan analisis data tentang informasi yang ada dalam spesifikasi dimasa depan. Teknik yang digunakan pada perancangan database ini dibagi dalam tiga tahapan, yaitu perancangan database konseptual, logical, dan fisikal.

\subsection{Conseptual Database Design}

Pada tahapan ini dilakukan untuk menentukan siapa saja yang terlibat dalam sistem, apa saja input yang diperlukan, informasi (output) apa yang diinginkan dari database[7] Secara terperinci seperti target DBMS, program aplikasi, bahasa pemrograman, hardware platform, performance dan segala pertimbangan fisikal lainnya[5]. Berikut adalah identifikasi tipe entitas dalam rancangan database konseptual seperti yang ditunjukkan pada Tabel 1, yaitu :

Tabel 1 Identifikasi Tipe Entitas

\begin{tabular}{|l|l|l|l|}
\hline No & Nama Entity & \multicolumn{1}{|c|}{ Keterangan Entity } & \multicolumn{1}{c|}{ Kegiatan } \\
\hline 1 & Member & $\begin{array}{l}\text { merupakan entitas yang } \\
\text { berisi data mengenai } \\
\text { member }\end{array}$ & $\begin{array}{l}\text { anggota dapat beberapa kali } \\
\text { melakukan peminjaman } \\
\text { barang }\end{array}$ \\
\hline 2 & Barang & $\begin{array}{l}\text { merupakan entitas yang } \\
\text { berisi data mengenai } \\
\text { barang }\end{array}$ & $\begin{array}{l}\text { setiap barang dapat dipinjam } \\
\text { oleh satu atau beberapa orang }\end{array}$ \\
\hline 3 & Petugas & $\begin{array}{l}\text { merupakan entitas yang } \\
\text { berisi data mengenai } \\
\text { petugas }\end{array}$ & $\begin{array}{l}\text { petugas dapat beberapa kali } \\
\text { melakukan pencatatan } \\
\text { peminjaman barang }\end{array}$ \\
\hline 4 & Peminjaman & merupakan entitas yang & dapat menyimpan hanya satu \\
\hline
\end{tabular}




\begin{tabular}{|l|l|l|l|}
\hline & & $\begin{array}{l}\text { berisi data mengenai } \\
\text { barang yang dipinjam }\end{array}$ & $\begin{array}{l}\text { data transaksi perpeminjaman } \\
\text { barang }\end{array}$ \\
\hline 5 & Pengembalian & $\begin{array}{l}\text { merupakan entitas yang } \\
\text { berisi data mengenai } \\
\text { barang yang } \\
\text { dikembalikan }\end{array}$ & $\begin{array}{l}\text { data menyimpan } \\
\text { pengembalian barang } \\
\text { berdasarkan transaksi } \\
\text { peminjaman }\end{array}$ \\
\hline 6 & $\begin{array}{l}\text { Detail } \\
\text { Peminjaman }\end{array}$ & $\begin{array}{l}\text { merupakan entitas yang } \\
\text { berisi data mengenai } \\
\text { detail barang yang } \\
\text { dipinjam }\end{array}$ & $\begin{array}{l}\text { satu transaksi bisa memiliki } \\
\text { lebih dari satu barang }\end{array}$ \\
\hline
\end{tabular}

Identifikasi tipe rasional bertujuan untuk menentukan hubugan-hubungan penting yang ada diantara jenis-jenis entitas yang telah diidentifikasikan sebelumnya [5]. Berikut adalah identifikasi tipe rasional dalam rancangan database konseptual seperti yang ditunjukkan pada Gambar 1, yaitu :

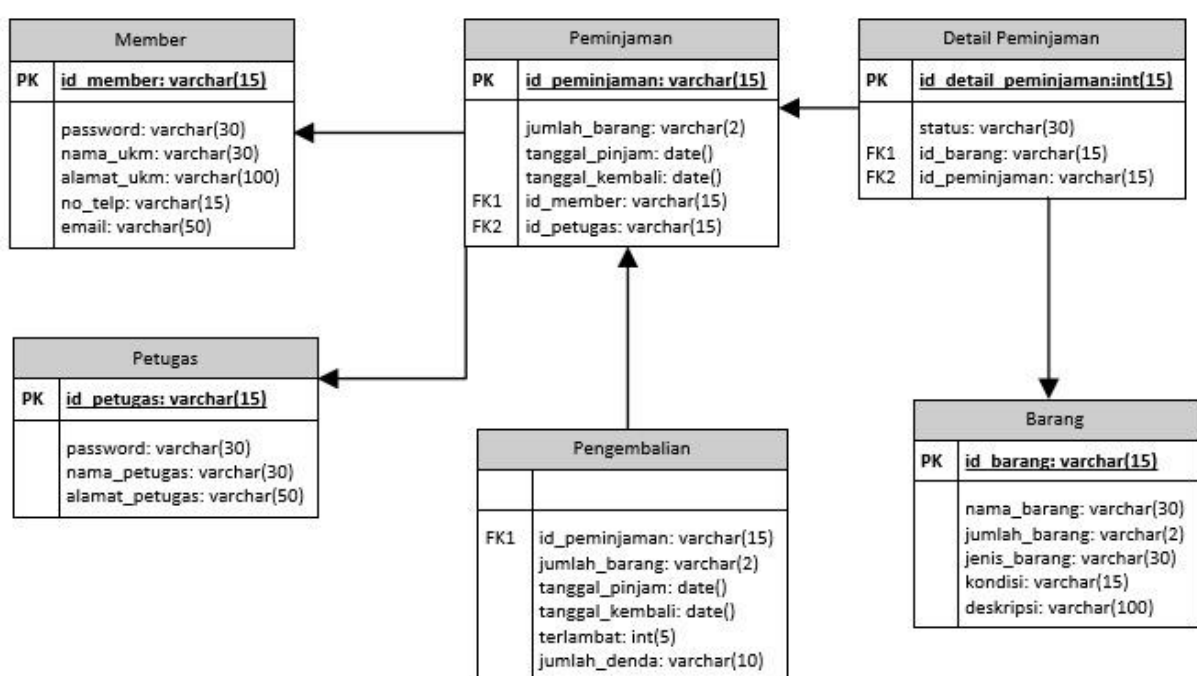

Gambar 1. E-R Diagram Konseptual

Domain adalah seluruh kemungkinan nilai yang dapat diberikan ke suatu atribut. Member nama domain yang sesuai dengan nilai yang akan dimiliki domain tersebut. Domain akan menentukan tipe data dari nilai yang nantinya akan membentuk domain dan menentukan format dari domain [4]. Berikut adalah identifikasi attribut domain dalam rancangan database konseptual seperti yang ditunjukkan pada Tabel 2, yaitu :

Tabel 2 Atribut Domain

\begin{tabular}{|l|l|l|}
\hline Entity name & Attribute & Domain \\
\hline Member & Id_member & $\begin{array}{l}\text { String dengan panjang maksimal 15 } \\
\text { karakter }\end{array}$ \\
\cline { 2 - 3 } & Password & $\begin{array}{l}\text { String dengan panjang maksimal 30 } \\
\text { karakter }\end{array}$ \\
\cline { 2 - 3 } & Nama_ukm & $\begin{array}{l}\text { String dengan panjang maksimal 30 } \\
\text { karakter }\end{array}$ \\
\cline { 2 - 3 } & Alamat_ukm & $\begin{array}{l}\text { String dengan panjang maksimal 100 } \\
\text { karakter }\end{array}$ \\
\hline
\end{tabular}




\begin{tabular}{|c|c|c|}
\hline & No_hp & $\begin{array}{l}\text { String dengan panjang maksimal } 15 \\
\text { karakter }\end{array}$ \\
\hline & Email & $\begin{array}{l}\text { String dengan panjang maksimal } 50 \\
\text { karakter }\end{array}$ \\
\hline \multirow[t]{6}{*}{ Barang } & Id_barang & $\begin{array}{l}\text { String dengan panjang maksimal } 15 \\
\text { karakter }\end{array}$ \\
\hline & Nama_barang & $\begin{array}{l}\text { String dengan panjang maksimal } 30 \\
\text { karakter }\end{array}$ \\
\hline & Jumlah_barang & $\begin{array}{l}\text { String dengan panjang maksimal } 2 \\
\text { karakter }\end{array}$ \\
\hline & Jenis_barang & $\begin{array}{l}\text { String dengan panjang maksimal } 30 \\
\text { karakter }\end{array}$ \\
\hline & Kondisi & $\begin{array}{l}\text { String dengan panjang maksimal } 15 \\
\text { karakter }\end{array}$ \\
\hline & Deskripsi & $\begin{array}{l}\text { String dengan panjang maksimal } 100 \\
\text { karakter }\end{array}$ \\
\hline \multirow[t]{4}{*}{ Petugas } & Id_petugas & $\begin{array}{l}\text { String dengan panjang maksimal } 15 \\
\text { karakter }\end{array}$ \\
\hline & Password & $\begin{array}{l}\text { String dengan panjang maksimal } 30 \\
\text { karakter }\end{array}$ \\
\hline & Nama_petugas & $\begin{array}{l}\text { String dengan panjang maksimal } 30 \\
\text { karakter }\end{array}$ \\
\hline & Alamat_petugas & $\begin{array}{l}\text { String dengan panjang maksimal } 50 \\
\text { karakter }\end{array}$ \\
\hline \multirow[t]{6}{*}{ Peminjaman } & Id_Peminjaman & $\begin{array}{l}\text { String dengan panjang maksimal } 15 \\
\text { karakter }\end{array}$ \\
\hline & Id_member & $\begin{array}{l}\text { String dengan panjang maksimal } 15 \\
\text { karakter }\end{array}$ \\
\hline & Id_Petugas & $\begin{array}{l}\text { String dengan panjang maksimal } 15 \\
\text { karakter }\end{array}$ \\
\hline & Jumlah_barang & $\begin{array}{l}\text { String dengan panjang maksimal } 2 \\
\text { karakter }\end{array}$ \\
\hline & Tanggal_pinjam & $\begin{array}{l}\text { Date dengan dengan panjang maksimal } \\
10 \text { karakter }\end{array}$ \\
\hline & Tanggal_kembali & $\begin{array}{l}\text { Date dengan dengan panjang maksimal } \\
10 \text { karakter }\end{array}$ \\
\hline \multirow[t]{6}{*}{ Pengembalian } & Id_Peminjaman & $\begin{array}{l}\text { String dengan dengan panjang maksimal } \\
15 \text { karakter }\end{array}$ \\
\hline & Jumlah_barang & $\begin{array}{l}\text { String dengan dengan panjang maksimal } \\
2 \text { karakter }\end{array}$ \\
\hline & Tanggal_pinjam & $\begin{array}{l}\text { Date dengan dengan panjang maksimal } \\
10 \text { karakter }\end{array}$ \\
\hline & Tanggal_kembali & $\begin{array}{l}\text { Date dengan dengan panjang maksimal } \\
10 \text { karakter }\end{array}$ \\
\hline & Terlambat & $\begin{array}{l}\text { Number dengan dengan panjang } \\
\text { maksimal } 5 \text { karakter }\end{array}$ \\
\hline & Jumlah_denda & $\begin{array}{l}\text { Number dengan dengan panjang } \\
\text { makmsial } 10 \text { karakter }\end{array}$ \\
\hline
\end{tabular}




\begin{tabular}{|l|l|l|}
\hline Detail_Peminjaman & Id_Detail_Peminjaman & $\begin{array}{l}\text { String dengan dengan panjang maksimal } \\
15 \text { karakter }\end{array}$ \\
\cline { 2 - 3 } & Id_Peminjaman & $\begin{array}{l}\text { String dengan dengan panjang maksimal } \\
15 \text { karakter }\end{array}$ \\
\cline { 2 - 3 } & Id_Barang & $\begin{array}{l}\text { String dengan dengan panjang maksimal } \\
30 \text { karakter }\end{array}$ \\
\cline { 2 - 3 } & Status & String dengan dengan panjang maksimal \\
& & 30 karakter \\
\hline
\end{tabular}

\subsection{Logical Database Design}

Perancangan logikal merupakan suatu tahapan yang digunakan untuk menentukan hasil perancangan konseptual ke dalam bentuk yang nantinya akan diimplementasikan dalam DBMS [8]. Berikut adalah hubungan antara barang dan peminjaman dalam rancangan database logikal seperti yang ditunjukkan pada Gambar 2, yaitu :
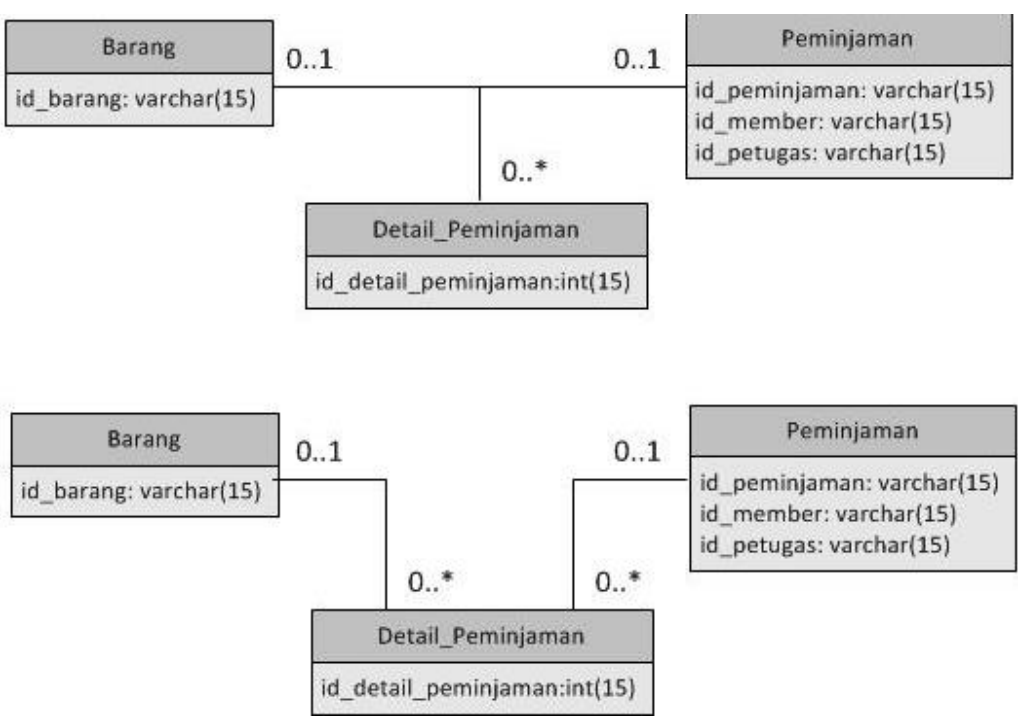

Gambar 2. Hubungan Barang dan Peminjaman

Normalisasi digunakan untuk meminimalisasikan adanya kemungkinan redundansi data, data yang tidak konsisten terutama jika menambah dan mengurangi data.

1. Bentuk Un-Normal

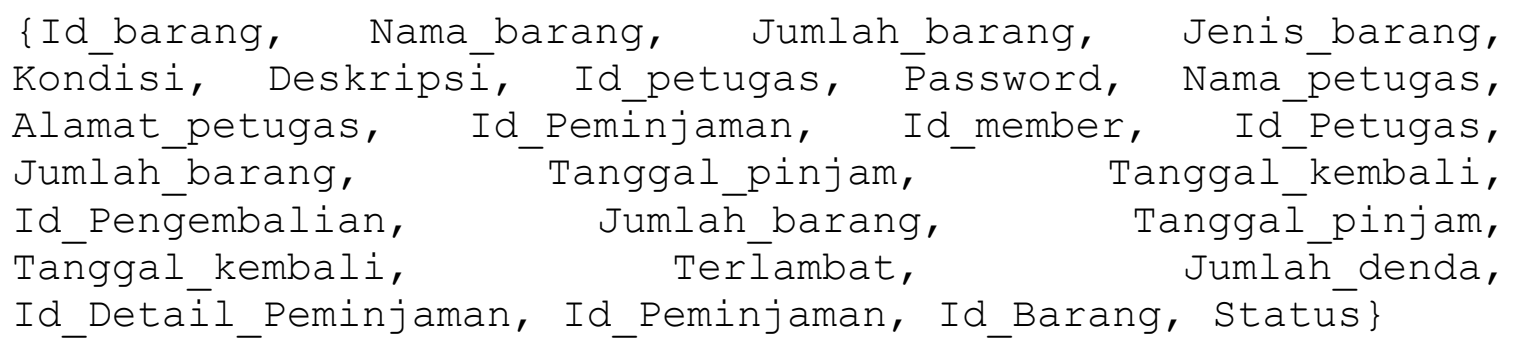

\section{Bentuk Normal Pertama}

Langkah berikutnya adalah dengan memisahkan atribut-atribut yang nilainya sama akan ditulis satu kali

Tabel member

$$
\begin{aligned}
& \{\text { Id_member, Password, Nama_ukm, Alamat_ukm, } \\
& \text { No_hp, Email }
\end{aligned}
$$


Tabel petugas

$$
\text { \{Id_petugas, }
$$

Password,

Nama_petugas, Alamat_petugas

Tabel barang

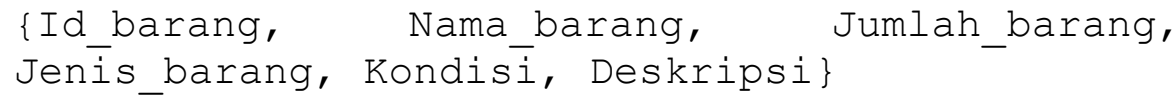

Tabel Peminjaman \{Id Peminjaman, Tanğgal kembali, Id Pengembalian, Terlambat, Jumlah_denda, Id_Detäil_Peminjaman, Status\}

3. Bentuk Normal Kedua

Langkah selanjutnya adalah dengan cara menentukan ketergantungan fungsional.

Tabel member \{Id_member, Password, Nama_ukm, Alamat_ukm, No hp, Email\}

Tabel petugas

\{ Id petugas, Alamat_petugas

Tabel barang

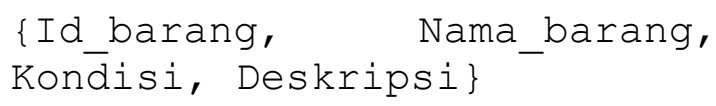

Tabel Peminjaman \{Id_Peminjaman, Jumlah_barang, Tanggal_pinjam, Tanggal_kembali, Id_Detail_Peminjaman Status\}

Tabel Pengembalian

\{Id_Pengembalian, Tanggal_kembali, Jumlah_barang, Jumlah_denda

4. Bentuk Normal Ketiga

Tabel Member $\quad$ *Id_member, Password, Nama_ukm, Alamat_ukm, No_hp, Email\}

Tabel Barang

\{ Id_barang, Nama_barang, Jumlah_barang,
Jenis_barang, Kondisi, Deskripsi\}

Tabel Petugas

$\left\{* I d \_p e t u g a s\right.$,

Password,

Nama_petugas, Alamat_petugas

Tabel Peminjaman $\{* I d$ Peminjaman, Jumlāh barang, TanggaI_kembali\}

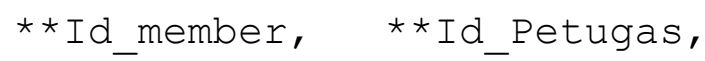
Tangga $\bar{l}$ pinjam,

$\{$ Id_Pengembalian, Tanggal_pinjam, Terlambat, Jumlah_denda\}

Tabel Pengembalian

Tabel Detail_Peminjaman $\left\{* I d \_\right.$Detail_Peminjaman, $\quad * *$ Id_Peminjaman, Jumlah_barang, Tanggal_k̄embali, **Id_Barang, Status

\subsection{Physical Database Design}

Pada tahapan perancangan database secara fisikal, tiap entitas ditentukan atribut beserta kelengkapannya seperti tipe data, panjang karakter, indeks, tipe relasi, dan kelengkapan lainnya. Dari perancangan fisikal ini dapat diperkirakan kapasitas penyimpanan database yang diperlukan [6]. Berikut adalah rancangan database fisikal seperti yang ditunjukkan pada Tabel 3 sampai 8. 
Tabel 3 Data Member

\begin{tabular}{|l|l|l|l|}
\hline Nama Field & Tipe & Ukuran & Keterangan \\
\hline Id_member & Varchar & 15 & Primary Key \\
\hline Password & Varchar & 30 & Not Null \\
\hline Nama_ukm & Varchar & 30 & Not Null \\
\hline Alamat_ukm & Varchar & 100 & Not Null \\
\hline No_hp & Varchar & 15 & Not Null \\
\hline Email & Varchar & 50 & Not Null \\
\hline
\end{tabular}

Tabel 4 Data Barang

\begin{tabular}{|l|l|l|l|}
\hline Nama Field & Tipe & Ukuran & Keterangan \\
\hline Id_barang & Varchar & 15 & Primary Key \\
\hline Nama_barang & Varchar & 30 & Not Null \\
\hline Jumlah_barang & Varchar & 2 & Not Null \\
\hline Jenis_barang & Varchar & 30 & Not Null \\
\hline Kondisi & Varchar & 15 & Not Null \\
\hline Diskripsi & Varchar & 100 & Not Null \\
\hline
\end{tabular}

Tabel 5 Data Petugas

\begin{tabular}{|l|l|l|l|}
\hline Nama Field & Tipe & Ukuran & Keterangan \\
\hline Id_petugas & Varchar & 15 & Primary Key \\
\hline Password & Varchar & 30 & Not Null \\
\hline Nama_petugas & Varchar & 30 & Not Null \\
\hline Alamat_petugas & Varchar & 50 & Not Null \\
\hline
\end{tabular}

Tabel 6 Data Peminjaman

\begin{tabular}{|l|l|l|l|}
\hline Nama Field & Tipe & Ukuran & Keterangan \\
\hline Id_Peminjaman & Varchar & 15 & Primary Key \\
\hline Id_member & Varchar & 15 & $\begin{array}{l}\text { Foreign Key } \\
\text { References } \\
\text { Member }\end{array}$ \\
\hline Id_Petugas & Varchar & 15 & $\begin{array}{l}\text { Foreign Key } \\
\text { References Petugas }\end{array}$ \\
\hline Jumlah_barang & Varchar & 2 & Not Null \\
\hline Tanggal_pinjam & Date & 10 & Not Null \\
\hline Tanggal_kembali & Date & 10 & Null \\
\hline
\end{tabular}

Tabel 7 Data Pengembalian

\begin{tabular}{|l|l|l|l|}
\hline Nama Field & Tipe & Ukuran & Keterangan \\
\hline Id_peminjaman & Varchar & 15 & $\begin{array}{l}\text { Foreign Key } \\
\text { References } \\
\text { Peminjaman }\end{array}$ \\
\hline
\end{tabular}




\begin{tabular}{|l|l|l|l|}
\hline Jumlah_barang & Varchar & 2 & Not Null \\
\hline Tanggal_pinjam & Date & 10 & Null \\
\hline Tanggal_kembali & Date & 10 & Not Null \\
\hline Terlambat & Int & 5 & Not Null \\
\hline Jumlah_denda & Int & 10 & Not Null \\
\hline
\end{tabular}

Tabel 8 Data Detail Peminjaman

\begin{tabular}{|l|l|l|l|}
\hline Nama Field & Tipe & Ukuran & Keterangan \\
\hline Id_Detail_Peminjaman & Varchar & 15 & Primary Key \\
\hline Id_Peminjaman & Varchar & 15 & $\begin{array}{l}\text { Foreign Key } \\
\text { References } \\
\text { Peminjaman }\end{array}$ \\
\hline Id_Barang & Varchar & 30 & $\begin{array}{l}\text { Foreign Key } \\
\text { References } \\
\text { Barang }\end{array}$ \\
\hline Status & Varchar & 30 & Not Null \\
\hline
\end{tabular}

Berikut ini adalah querry relasi dari beberapa tabel yang yang paling sering digunakan seperti ditunjukan dibawan ini:

1. Tabel Peminjaman

SELECT * FROM peminjaman

peminjaman.id_member=member.id_member

peminjaman.id_petugas=petugas.id_petugas

2. Tabel Detail Peminjaman

SELECT * FROM detail_peminjaman JOIN peminjaman ON detail_peminjaman.id_peminjaman=peminjaman.id_peminjaman JOIN barang ON detail_peminjaman.id_barang=barang.id_barang

3. Tabel Pengembalian

$\begin{array}{lllll}\text { SELECT } & * & \text { FROM pengembalian JOIN peminjaman } & \text { ON }\end{array}$ pengembalian.id_peminjaman=peminjaman.id_peminjaman

\section{Kesimpulan}

Berdasarkan hasil dari perancangan database peminjaman barang di Universitas XYZ, maka dapat disimpulkan sebagai berikut:

1. Menghasilkan rancangan basis data konseptual yang terdiri dari 6 entitas beserta attribut domain pada setiap nama entitas, dan diargam hubungan antar entitas yang digambarkan pada ER Diargam konseptual

2. Menghasilkan relasi untuk model data logikal lokal yang mempresentasikan hubungan antar suatu entitas dengan entitas lainnya dan dinormalisasikan untuk memastika tidak adanya pengulangan data

3. Menghasilkan rancangan database dalam bentuk berdasarkan tipe data, ukuran dan keterangan data. Jumlah tabel dalam basis data peminjaman barang ada 10 buah. 


\section{Daftar Pustaka}

[1] A.S Rosa Dan M. Salahuddin. Modul Pembelajaran Rekayasa Perangkat Lunak (Terstruktur Dan Berorientasi Objek), Modula, Bandung, 2011

[2] I. Khasbi, F. Nugraha, S. Muzid, Sistem Informasi Peminjaman Ruang Dan Barang Di Universitas Muria Kudus Berbasis Web Menggunakan Fitur Sms Notification, Jurnal Simetris, Vol 7 No 2, 2016

[3] D.Yusuf, 2017 Sistem Peminjaman Barang Di Perusahaan Menggunakan Teknologi Rfid, Jurnal SIGMA, Vol. 6, No. 1. Halaman 49 - 58. 2017

[4] W.S Prasetya, Perancangan Model Basis Data Relasional Dengan Metode Database Life Cycle, Seminar Nasional Informatik 2015, Stmik Pontianak, Pontianak, 2015

[5] Gat, Perancangan Basis Data Perpustakaan Sekolah Dengan Meerapkan Model Data Relasional, Jurnal Citec, Vol. 2, No. 4, 2015

[6] F.S Handayani, M.P Putri, Perancangan Basis Data Instrumen Bimbingan Konseling Alat Ungkap Pemahaman Diri Siswa, Journal Citec, 2017

[7] A. Kurniati, Angguningtyas, R.G Isnanda, Perancangan Database Pada Sistem Asessmen Dan Pemetaan Hasil Asessmen Berbasis Tag Sebagai Pembantu Penyusunan Strategi Pembelajaran, Jurnal Ilmiah Semesta Teknika Vol. 20, No.2, 106-115, 2017

[8] D.P Putra, Analisis Dan Perancangan Basis Data Penjualan, Pembelian Dan Persediaan Barang Pada Cv. Cemerlang Jaya, Universitas Bina Darma, 2013 